\title{
A Case Study on the Usage of the Value Blueprint for Ecosystem Design
}

\author{
Luciana A. Almeida \\ Federal University of Pará \\ 66075-110 - Belém - PA - Brazil \\ (91) 32017112 \\ lu.abdon.si@gmail.com
}

\author{
Cleidson R. B. de Souza \\ Vale Institute of Technology and \\ Federal University of Pará \\ 66055-080 - Belém - PA - Brazil \\ (91) 3213-5571 \\ cleidson.desouza@acm.org
}

\author{
Adailton M. Lima, Rodrigo Reis \\ Federal University of Pará \\ 66075-110 - Belém - PA - Brazil \\ adailton@ufpa.br, \\ quites@ufpa.br
}

\begin{abstract}
Ecosystems are an important aspect of today's software business. Different companies aim to create an ecosystem around their products so that they can benefit from this. Unfortunately, creating such ecosystems is not an easy task. One of the few tools that can be used to facilitate this process is Adner's Value Blueprint. This tool allows a company to identify the different types of risks that it faces during the establishment of an ecosystem. Adner presents several examples of blueprints he has built and provides some guidelines to create new ones. Given the potential of the approach in addressing some of the issues faced by ecosystem designers, we decided to assess the usage of the Value Blueprint through a case study using data from the Apple Watch ecosystem. We report our results from the Apple ecosystem, and more importantly, our evaluation of the value blueprint tool. We conclude by providing recommendations for practitioners interested in establishing their own ecosystems and researchers interested in the design of ecosystems.
\end{abstract}

\section{Categories and Subject Descriptors}

D.2.9 [Management]: Life cycle; H.1.m [Miscellaneous]; K.1 [Markets]; K.6.1 [Project and People Management]: Strategic Information Systems Planning

\section{General Terms}

Management, Design, Economics, Human Factors.

\section{Keywords}

Business Ecosystem, Ecosystem Design, Value Blueprint.

\section{INTRODUCTION}

Nowadays, innovation is a key point to any company that wishes to remain competitive. In the past, innovation depended exclusively on the company itself. Today, "in an increasing number of industries, the interdependence of various products and the widespread ability for many actors to innovate require that every company, no matter how big or how small, makes its fundamental decisions while taking into account what every other company active in the network of interlocking parts is doing" [1]. In other words, today a company's success does not rely only on the internal capacity of an organization to live up to its own promises, but also there is a increasing recognized importance of

Permission to make digital or hard copies of all or part of this work for personal or classroom use is granted without fee provided that copies are not made or distributed for profit or commercial advantage and that copies bear this notice and the full citation on the first page. To copy otherwise, or republish, to post on servers or to redistribute to lists, requires prior specific permission and/or a fee.

SBSI 2015, May 26-29, 2015, Goiânia, Goiás, Brazil.

Copyright SBC 2015. the role of collaborators, which can be visible or not, and can be willing or not to fulfill their promises. The term business ecosystem is often used to refer to this new scenario. While there are several definitions of business ecosystems, this text will adopt the definition by Moore [2]: "a business ecosystem is a dynamic structure of interconnected organizations that depend on each other for mutual survival." This means that a business ecosystem is an economic community supported by a foundation of organizations and individuals, who interact through assets and services and produce value to customers. These customers are also part of the ecosystem along with suppliers, input producers, competitors and other stakeholders.

In this new scenario companies need to be able to identify, understand and act upon their dependencies since they need to develop strategies that will lead to their success [3]. In fact, the history of significant failures and unexpected successes in the context of business ecosystems is quite enlightening. According to Adner [3], an example of a significant failure is Sony's digital reader, a groundbreaking device from a hardware point of view, which failed since the e-books ecosystem was still under development when it was delivered to the market. On the other hand, in the same context, Adner cites Amazon's digital reader, the Kindle, which revolutionized the e-books market by being launched alongside a consolidated ecosystem, even though it was released later than Sony's product.

The need to deal with the explicit or implicit dependencies of a business ecosystem is recognized as something important. Gawer and Cusumano [1], for instance, discuss a framework to be used by companies that want to lead innovation in their industries. Similarly, Eisenmann, Parker and Alstyne [4] discuss how relationships among ecosystem parties might allow one provider in one platform market enter another platform market, which is called platform envelopment. However, most of the research in the area is based on analysis of industrial case studies. Only a few have been written about the description of the required steps for a company to manage the dependencies among ecosystem parties in the beginning of a process. An exception is the work by Adner [3] that proposes a tool, the Value Blueprint, which aims to identify the risks associated with the creation of a successful ecosystem.

In our work we are interested in developing an enterprise business ecosystem, i.e., an ecosystem that will be used solely within our own organization. However, differently from other studies [5], this ecosystem and, most importantly, the applications to be built on this ecosystem will be built from the scratch. Therefore, we started to look for recommendations, guidelines or methodologies about how to manage the dependencies that should be taken into account when designing our own ecosystem. As mentioned, Adner's value blueprint [3] was among the few identified. It allows one to investigate the risks associated with ecosystem 
design especially those risks associated with implicit and explicit dependencies. Therefore, we decided to assess the value blueprint, which is done through a case study. We decided to focus on the development of innovative ecosystems, and for this reason the Apple Watch $[6,7]$ case has been chosen. Since we do not have access to internal Apple's employees, our data collection was based on data available in the news, articles and the product description currently available at Apple's website.

The rest of this paper work is organized as follows. Section 2 briefly reviews the Business Modeling and Ecosystem Design themes. Section 3 introduces the concepts related to designing Ecosystems using the Value Blueprint tool. Thus, in section 4 the context of our research is addressed, explaining the case study and the reason for its choice. Section 5 presents the methodology, in which the case study development steps are described. After that, section 6 presents the outcomes of the case study, which is followed by a discussion on section 7. Finally, in section 8 the final comments are outlined, as well as future work.

\section{BUSINESS MODELING AND ECOSYSTEM DESIGN}

We surveyed the literature aiming to find out approaches that would allow one to design business ecosystems, i.e., approaches that during the planning of a product or business would model ecosystem components similarly to the value blueprint.

One of the most used tools for creating and representing business models is the Model Business Canvas [8, 9] that is based on previous work from Osterwalder [10]. This tool is used to model, document and present business models. A canvas is composed of nine different components, one of them being the partners required to implement a particular business model. Osterwalder e Pigneur [9] argue that one needs to understand the context of the organization to create successful businesses. However, the model business canvas does not take into account the broader "context", i.e. the ecosystem, where this business is embedded.

There are several adaptations of the model business canvas including the Lean Canvas proposed by Maurya [11]. This model adds a few boxes to the model while removing others. While in one hand, she discusses execution, risks associated with the business model, on the other, she removes the box "Key Partners" which, as discussed by Adner, is very relevant in the context of business ecosystems. Maurya argues that she removed that because she believes that most start-ups do not require several partners early on. Therefore, in short, her work still focuses solely on execution risks, ignoring the co-innovation and adoption chain risks.

Another practitioner, Rod King [12], proposes a different adaptation of the model business canvas called Organizational Development Canvas (ODC). The main difference in this case is that King suggests that the ecosystem surrounding the business should be taken into account, so that partners, supplies and inputs are represented in the canvas as different components. In this regard, ODC is similar to the value blueprint, although it does not model relationships among parties as well as their engagement status (see next section).

A final extension was proposed by Sniukas [13] who argues that the canvas should be updated with the current business "context", since oftentimes businesses are embedded in ecosystems of partners, suppliers and other parties. In this case, this modified canvas focuses not only on the value proposition for the customer, but also on value creation for the company and its partners. Sniukas argues that one should identify the required partners for his/her business model and carefully manage the relationship with them. Risk is not explicitly represented as in the value blueprint, but it is implicit in the discussion.

In the following section, we will present the value blueprint tool, a tool aimed to help design business ecosystems and that takes into account partners, suppliers, and other involved parties as well as explicit represents risks associated with these parties.

\section{DESIGNING ECOSYSTEMS USING THE VALUE BLUEPRINT}

\subsection{Co-innovation and adoption chain risks}

A fundamental aspect of any innovative product is that there should be a value proposal, i.e., a promise. In order to fulfill this promise, it is necessary to find a way to translate the value proposition into an action. This means that a company needs to make the convergence of the necessary elements, i.e., to identify the stakeholders who need to work together to fulfill the promise, as well as to map the risks associated with the project and the severity of each one of them.

Many projects place their emphasis only on their execution efforts. As anyone can expect, these are certainly important. However, Adner [3] argues that innovative projects in the context of ecosystems should have a wider focus and identify additional risks. To be more specific, Adner identifies two additional risks beyond the execution risks: co-innovation risks and adoption chain risks. Co-Innovation risks consist of externally developed technologies or approaches that should exist so that the company product is successful. Adoption chain risks refer to all the participants in the value chain that should adopt the innovation so that the customer can have the opportunity to recognize the value proposal. These additional risks are essential in the context of business ecosystems. In fact, Adner presents several examples of products successes, and failures, because these additional risks were identified, or ignored. These examples illustrate how important is the adoption of an approach that allows one to assess the alternative configurations for the business, and helps to develop a shared comprehension and understanding among the stakeholders about how the parties of a ecosystem should be integrated and collaborate so that the product, and ultimately the entire ecosystem, is successful.

\subsection{The Value Blueprint}

In order to identify, document and reason about risks, Adner proposes a mapping tool called value blueprint. This tool provides an overview of the parties required to deliver the value proposal of a product as well as different types of risks associated with it. Its differential lies on not focusing only on the linear sequence of suppliers, producers, distributors and end-customers: all the complementary parties (suppliers, partners, etc) that are fundamental to the product's success are taken into account even though they are not in the direct path to the market. Adner [3] argues that the use of traditional tools may neglect the existence of these parties, with the potential to generate blind spots that may hinder the innovation.

In addition to identifying additional parties, the value blueprint informs the extent to which these parties are aligned with the product to be released. In this case, Adner uses a simple metaphor, 
based on the continuous traffic sign represented by green-yellowred lights, to indicate the alignment of each party. For the coinnovation risks, green means the associated parties are ready and in place; yellow means that they are not yet in place, but that there is a plan (that can take a while, but which will be achieved eventually); and red means that these parties are not in place and there is no clear plan set for them. For the adoption risks, green means that a party is looking forward to participating; yellow means that they are neutral, but open to entering in the business ecosystem; and red means that they have clear reasons to maintain their previous condition not participating in the ecosystem the way it is laid out.

Adner [3] explains that it is rare for an innovative product to start with all the lights green. That is not mandatory, either. Yellow lights are acceptable, as long as they are followed by a plan to make them turn into green. Red lights, though, are challenging. Any red light appearing on the map, either by lack of capacity of a collaborator to deliver or by lack of will to cooperate, or due to a problem of its own, must be addressed. This may represent a set of arrangements that can be made, such as the managing of incentives to find a way to overcome problematic connections in the project.

To a certain extent, the traffic sign metaphor intuitively illustrates the severity of each risk associated with a particular party, therefore it clearly indicates to the product's owner the amount of effort necessary with the parties so that they can join the ecosystem. It is worth to point out that many times, in order to identify the most promising path in the business ecosystem, an iterative process of identification and evaluation of parties is carried out. Thus, only after all the adjustments have been made it is possible to reliably connect the elements.

\subsection{Example of a Value Blueprint}

In this section, we will briefly present an example of a value blueprint to illustrate how this tool can be used. This example is presented in Figure 1 below.

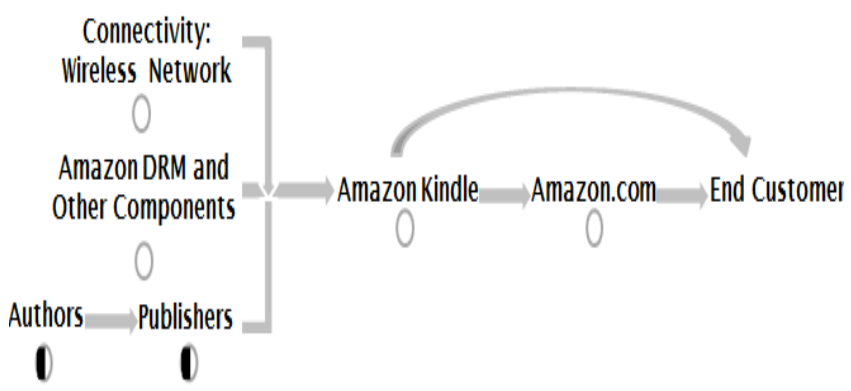

$$
\text { O creen light Yellowight Redlight }
$$

Figure. 1. Amazon's Kindle Value Blueprint during its launch. Adapted: ADNER [3]

As it can be seen, in Kindle's value blueprint the initial complementors have been identified: (i) the wireless connectivity in the device developed, which would allow for the utilization of Amazon's network to download the book instantaneously, (ii) the use of a closed and proprietary architecture, which in turn would reduce the risks of adoption by the editors and authors (with yellow lights), for preventing the books from being copied, printed, or put available in other (illegal) means. Furthermore,
Kindle offered a complete experience initially including 90,000 titles in its library and had significantly reduced the prices of the e-books in comparison to the printed items, therefore making a profit in return with the sales of the device. Thus, as one can perceive the plan to transform the yellow lights in green ones was being designed, i.e., a plan to address the identified risks. In the end, Amazon designed a winner ecosystem where all the collaborators (publishers and authors) could benefit from a satisfactory slice of Kindle's sales.

\subsection{Identifying the Value Blueprint elements}

The Value Blueprint consists of a map in which all the components for a minimum viable ecosystem (MVE) ${ }^{1}$ are clearly laid out, as shown in the example of section 3.3. It establishes the arrangement of the elements needed to deliver the value proposal, how they are positioned and their relations. Table 1 summarizes the steps, suggested by Adner [3], for identification of the coinnovation and adoption chain risks for the construction of a value blueprint. Once the relationships are identified and mapped in the blueprint, it is possible to have an overview of all the parties involved in the ecosystem alongside the challenges which are beyond the company's own immediate responsibilities. The blueprint also allows one to consider how(s) he wants to manage the risks that are inherent to the collaboration efforts, proactively dealing with them.

After presenting the tool we used in this work, the following section will explore the research context in which the case study was performed.

\section{RESEARCH CONTEXT}

Adner presents several examples of value blueprints in his book including Apple's iPod and iPhone, Nigeria's M-Pesa, Amazon's Kindle, among other products. As summarized in Table 1, Adner also presents some recommendations to be used during the creation of one's own ecosystem.

We decided then to follow these recommendations as a way to assess the creation of value blueprints as well as the blueprints themselves. Therefore, we chose to create a value blueprint for the Apple Watch (Figure 2). Although, this is not the first of its kind, it is expected to give birth to a family of products by Apple [6]. We chose Apple due to its good track of success in the context of business ecosystems in the last years [3]. Another reason for choosing this product is that in our own company, we are exploring the usage of wearables for our internal purposes ${ }^{2}$. Therefore, we hoped that creating such an ecosystem could provide a good starting point for our own project.

According to the reports about the Apple Watch, many challenges were found during its development, such as the physical design and miniaturizing of its components, the creation or adaptation of an operating system, the pressure-sensitive retina screen, the API design for third-party apps, among others. As explained in the previous section, when using a value blueprint, however, it is also possible to understand the co-innovation and adoption chain risks associated with this product.

\footnotetext{
${ }^{1}$ Adner defines a minimum viable ecosystem (MVE) as "the simplest ecosystem [one can] assemble and still create some new value" [2, pg. 198].

${ }^{2}$ We can not detail our scenario due to confidentiality reasons.
} 
Table 1. Steps for identification of Value Blueprint elements. Adapted from ADNER p. 64 [3]

\begin{tabular}{|c|c|}
\hline $\begin{array}{l}\text { 1. Identify your end } \\
\text { customer. }\end{array}$ & $\begin{array}{l}\text { "Who is the final target of the value } \\
\text { proposition? Who ultimately needs } \\
\text { to adopt our innovation for us to } \\
\text { claim success?" }\end{array}$ \\
\hline $\begin{array}{l}\text { 2. Identify your own } \\
\text { product. }\end{array}$ & "What is it that we need to deliver?" \\
\hline 3. Identify your suppliers. & $\begin{array}{l}\text { "What inputs will we need to } \\
\text { construct our offer?" }\end{array}$ \\
\hline $\begin{array}{l}4 . \quad \text { Identify } \\
\text { intermediates. }\end{array}$ & $\begin{array}{l}\text { "Who stands between us and the end } \\
\text { customer? Who touches our } \\
\text { innovation after us, and to whom do } \\
\text { they pass it on the way to the end } \\
\text { customer?" }\end{array}$ \\
\hline $\begin{array}{l}\text { 5. Identify your } \\
\text { complementors. }\end{array}$ & $\begin{array}{l}\text { "For each intermediary ask: Does } \\
\text { anything else need to happen before } \\
\text { this intermediary can adopt the offer } \\
\text { and move it forward to the end } \\
\text { customer?" }\end{array}$ \\
\hline $\begin{array}{l}\text { 6. Identify the risks in the } \\
\text { ecosystem. }\end{array}$ & $\begin{array}{l}\text { For every element on the map ask: } \\
\text { "- What is the level of co-innovation } \\
\text { risk this element presents-how able } \\
\text { are they to undertake the required } \\
\text { activity? What is the co-innovation } \\
\text { risk level this element represents?" } \\
\text { "- What is the level of adoption risk } \\
\text { this element presents-how willing } \\
\text { are they to undertake the required } \\
\text { activity?" }\end{array}$ \\
\hline $\begin{array}{l}\text { 7. For every partner } \\
\text { whose status is not green. }\end{array}$ & $\begin{array}{l}\text { "Work to understand the cause of } \\
\text { the problem and identify a viable } \\
\text { solution." }\end{array}$ \\
\hline $\begin{array}{l}\text { 8. Update the blueprint on } \\
\text { a regular basis. }\end{array}$ & $\begin{array}{l}\text { "Your value blueprint is a live } \\
\text { document, and as conditions change } \\
\text { over time, it will need to be modified } \\
\text { accordingly." }\end{array}$ \\
\hline
\end{tabular}

\section{METHODOLOGY}

\subsection{Case Studies}

Case studies are an appropriate qualitative research method that allows researchers to deeply investigate an issue within a limited timeframe [14]. A case study is adequate for this work since it enables an analysis of the value blueprint tool in a context where there is a large variety of factors and relationships that can be directly observed, but that cannot be controlled. In addition, it was possible to build the value blueprint of Apple Watch ecosystem based on Adner's steps described on Table 1.

According to Gil [15], qualitative research can be: exploratory, descriptive, or explanatory. The context of this research has an exploratory nature, because it involves analysis of data that stimulates the comprehension and allows for an enhanced familiarity with the issue so as to make it explicit. In addition, according to Strauss and Corbin [16] this type of research is composed of three main components: data, procedures and reports. In short, data can derive from several sources, such as interviews, observations, documents or video recordings. The procedures are used to interpret and organize the data and finally, the written or verbal reports are utilized to present the results achieved.

\subsection{Our Case Study}

Our data collection was exclusively performed by exploratory qualitative procedures, extracting data available in the Internet (especially Apple's website) and from Adner's book [3]. Other data collection methods were not viable due to the case selection, i.e., interviewing or observing Apple developers and management personnel would had the potential to uncover a number answers for this study. However, this is not easily achievable.

In addition, it is important to mention that Adner presents the value blueprint for other Apple products, including the iPod, iPad and iPhone [3]. So, instead of starting the data collection step from the scratch, we used some of the ideas from these blueprint to refine the search we performed in the internet. For instance, we specifically searched for companies that would be Apple's partners in the context of the Apple Watch, since previous Apple's products were often launched with an initial set of partners. Based on Apple's previous ecosystem components and on the steps suggested by Adner to create a value blueprint (described on Table 1), a set of keywords were used to retrieve content from the internet. The resulting data was grouped in the two types of risks suggested by Adner [3]. We also studied each one of the components in order to identify the possible risks associated with them, and therefore defined the "risk colors" for those components. Having done that, we were able to develop Apple's Watch Value Blueprint, which is presented in the next section.

\section{RESULTS}

In this section all the data collected are illustrated as categories of either co-innovation risks or adoption chain risks. Based on the identification of these risks, we will also present what we believe is Apple Watch minimum viable ecosystem. With the construction of such ecosystem, it is also possible to provide an initial evaluation with the positive and negative sides of the value blueprint tool in the context of designing business ecosystems.

The keywords identified in the data collection phase are classified as co-innovation and adoption chain risks, identified as key elements for the construction of the value Blueprint for the Apple Watch, as can be seen in Table 2. In the following paragraphs, we detail each one of the risks we identified as well as reported by Adner.

The co-innovation risk is the "measure in which the success of an innovation depends on the trading of other innovations" [3]. Therefore, by assessing the Co-Innovation risks we can observe that the Apple Watch is a device that is launched already with a dependency, since it requires an iPhone 5 or a higher-performing device to complement its functionalities. This kind of dependency illustrates the vision of Apple's devices lying in the ecosystem and no longer on the concern of just fitting parts together [17].

Adner also discusses a strategic aspect that he calls ecosystems carryover, in which the consolidation of an ecosystem is used to create advantage over a new ecosystem. An example would be how the iPhone leverage iPod's ecosystems. In the scenario of the Apple Watch, the convergence of innovations for creating another ecosystem is similar. For instance, one important new value proposition of the Apple Watch is that with this device the user can control all other Apple devices, like iTunes playlists, Apple's TV channels, and so on. These functions only add value if such 
products have good acceptance in the market, which is true in some cases.

Other co-innovation risks identified in the blueprint are the new technologies developed to allow the promised user experience including Accelerometers; Infrared LEDs; Photo Sensors; Touch Force; TapTic Engine; Flexible Screens; Inductive Loading and MagSafe. Technologies as WiFi, GPS and Bluetooth also compose the Apple Watch value proposal, which create a coinnovation risk due to the demand of adaptation to the device's peculiarities. These technologies are necessary for Apple's Watch value proposal and therefore, should also be considered as project execution risks, which are also part of the value blueprint.

Table 2. Co-Innovation and adoption Chain risks of Apple Watch. Items followed by $*$ are items already identified by Adner in his previous analysis of Apple's products ecosystems.

\begin{tabular}{|c|c|c|}
\hline $\begin{array}{l}\text { Co-Innovation } \\
\text { Risks }\end{array}$ & $\begin{array}{l}\checkmark \\
\checkmark \\
\checkmark \\
\checkmark \\
\checkmark \\
\checkmark \\
\checkmark\end{array}$ & $\begin{array}{l}\text { Sales of iPhone } 5 \text { or higher; } \\
\text { Apple Pay; } \\
\text { Passbook; } \\
\text { iTunes software*; } \\
\text { Apple TV Software; } \\
\text { Technologies specially developed } \\
\text { for the device: } \\
\quad \text { O Accelerometer; } \\
\circ \quad \text { Infrared LEDS; } \\
\circ \quad \text { Photo Sensors; } \\
\circ \quad \text { Touch Force; } \\
\circ \quad \text { TapTic Engine; } \\
\circ \quad \text { Flexible screens; } \\
\circ \quad \text { Inductive loading and } \\
\text { Hardware; } \\
\text { O WiFi; } \\
\circ \quad \text { GPS; } \\
\circ \quad \text { Bluetooth. }\end{array}$ \\
\hline $\begin{array}{l}\text { Adoption Chain } \\
\text { Risks }\end{array}$ & $\begin{array}{l}\checkmark \\
\checkmark \\
\checkmark \\
\checkmark \\
\checkmark \\
\checkmark \\
\checkmark\end{array}$ & 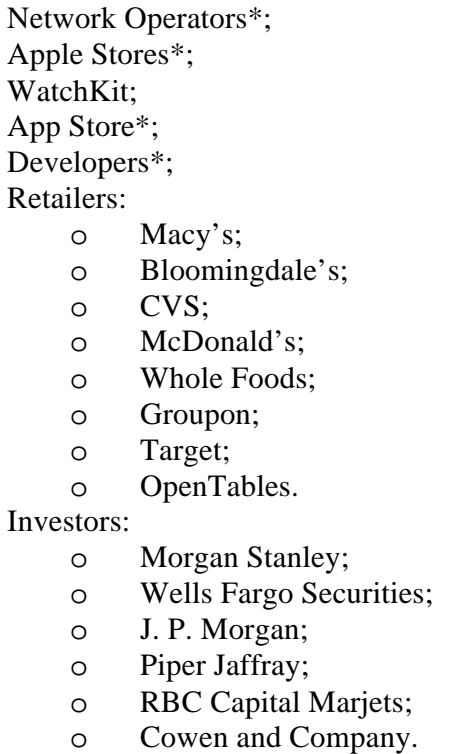 \\
\hline
\end{tabular}

The adoption chain risk is the "measure in which the partners will have to adopt your innovation, even before it has reached the clients" as defined by Adner [3]. In this case, this situation is easier to understand when one recognizes that Apple's usual plan is to induce existing consumers and partners to buy new products and move to the new associated ecosystem (again, the ecosystem carryover strategy) based on the value proposal of this new product. In this same context, we can find the Apple Pay and Apple Watch. Apple Pay is the electronic payment system launched by Apple. Nearly a week later its launch, there was "over 1 million credit card activations in its first 72 hours" according to Apple CEO's report and based on the data provided by Visa and MasterCard [18]. The Apple Pay is available for the iPhone 6 and will be available for the Apple Watch, therefore likely carrying along a number of investors and retailers. In other words, why the retail giants would be willing to invest double their digital panels in the stores? To attract Apple customers who look for this service, otherwise, they may end up losing more money for not being adequate to the new market [19]. An important fact is that an iPhone 6 user is able to perform purchases with Apple Pay-enabled retailers and it is supposed that millions of users will behave this way around the world [19]. A clear inference is to imagine that iPhone users will be able to benefit from these experiences if they also purchase the Apple Watches.

A good ecosystem designer understands that the motivation for complementors is crucial for them to stay in the ecosystem because an ecosystem success leader knows this should be a winwin game [3]. In this case, it is important to mention that the new technologies associated with the Apple Watch and the associated ecosystem also increase the likelihood of an ecosystem carryover among the software developers through the WatchKit, which offers new tools and APIs for the developers to create unique wrist-driven experiences [20].

Software for the Apple Watch will be provided through the App Store since the carryover approach is central to the Apple's strategy [3], i.e., an user can still use his previous software, apps and music. This is similar to what Apple did for the iPod, iPhone and iPad. This strategy allowed Apple to reach success with the iPhone MVE before the permission to third party developers to participate actively in the ecosystem [3]. On the other hand, this strategy generates risks in the adoption chain since it is closely related on how innovative is the proposal to make developers be motivated to contribute even before the product is released.

Figure 2 shows the value Blueprint for the Apple Watch MVE. The co-innovation risks and the adoption chain risks are shown in this figure, helping to avoid what Adner calls hidden risks, i.e., "while the managers have robust processes to assess and manage their own performance challenges, they do not fully understand their dependency on their partners co-innovation challenges".

We answered the questions defined in Table 1 to create the Value Blueprint. The product is identified, the Apple Watch. The suppliers are characterized as all those who offer inputs for the product construction, like the inputs for new technologies as mentioned in Table 2, the elaboration of WatchKit for the developers and the investors feel challenged and interested in seeing the results for themselves with the innovation. The intermediates are the retailers, like Apple Store and the network operators. The complementors parties are those who many times are not in the managers' field of vision; they are the retailers who are willing to adopt the Apple Pay system, which constitutes one of the value proposals, the airline companies who accept to enable their boarding passes through the Passbook, the developers who write apps for the product and leads the product to have even more value proposals to the users. And as an end-user, the iPhone users have been identified, as well as supporters of services, such as Apple Pay, Apple TV, iTunes among others launched by Apple itself. 


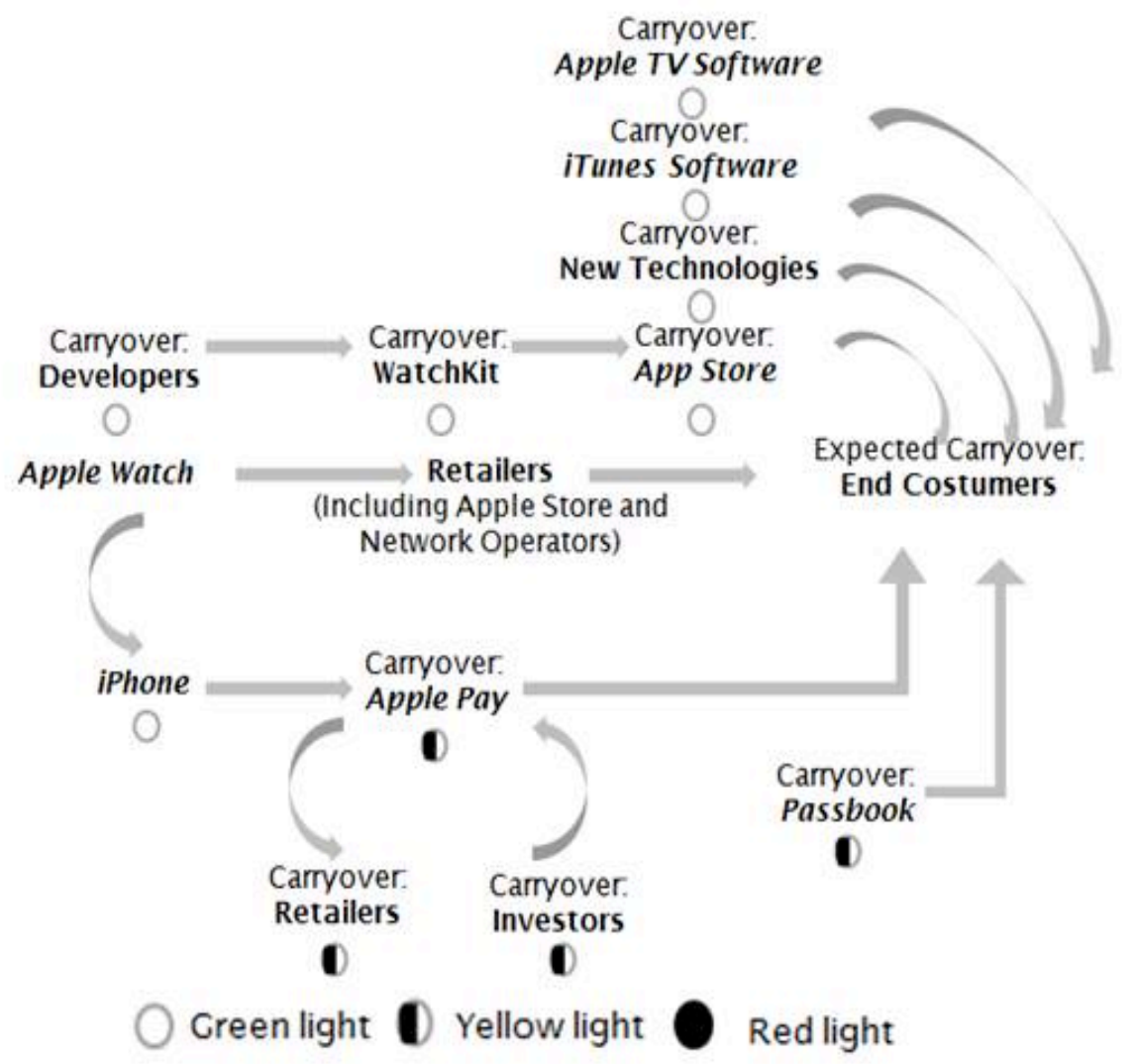

Figure. 2. Value Blueprint for the Apple Watch

The creation of a value blueprint does not mean that the innovation will be a success. However, its creation allows one to analyze a whole range of possibilities regarding its success, or failure, depending on the components of the ecosystem and their alignment with the product's value proposal (the red, yellow and green lights). In the case of the Apple Watch, one can notice that not only the product was carefully designed, but also the entire ecosystem was designed to be successful.

\section{Discussion}

Our initial evaluation of the value blueprint tool is that it is a simple, easy to understand and yet powerful tool to design business ecosystems. Our assessment is based on the fact that the notation used to express the blueprints contains only three types of graphical components: business parties (partners, complementors, etc), their status regarding the product (the risk severity), and the relationships among them. In some parts of the book, however, we noticed that the relationships in the book are represented as both solid and dotted lines, without a clear description of the difference between them. Therefore, when constructing Apple's Watch value blueprint, we decided to use one simple notation, the solid line, since it is the one most used.

The value blueprint examples and the description of the steps for creating value blueprints provided by Adner, and summarized on Table 1, are very clear. Despite the examples in the book, we faced several challenges during the creation of our first value blueprint. For instance, Adner argues that all elements mentioned on Table 1 (section 2.2) should be taken into account. However, the identification of the business parties is informal and very subjective, i.e., it depends on the person constructing the blueprint. The only guaranteed common parts among blueprints created by different people would be the beginning of the blueprint - the product -and its end - the customer. Furthermore, identifying the relationships among the different blueprint components is not straightforward since these are business relationships. Another challenge we faced was the time and effort required to create a blueprint: it is not as simple task, and required the first author four weeks to do so even though, as mentioned, Apple's Watch blueprint was based on similar Apple's blueprints from Adner [3]. We believe most of these issues arise from the fact that we are computer science professionals, and therefore had limited knowledge of business aspects. For instance, the distinction among different ecosystem parties (suppliers, intermediates, complementors, and partners) sometimes was not as straightforward.

Overall, we believe that there is an interesting opportunity for additional research in the context of value blueprints. For instance, different types of parties (suppliers, intermediates, complementors, and partners) could be modeled differently, i.e., with a notation for each one. Relationships themselves could also represent different types of information based on these types of parties. The overall goal of doing this is to allow automatic reasoning about blueprints using these new constructs. For instance, in blueprints with dozens of components, it would be possible to identify the most important components, the degree of relationships among them among other aspects. 
Finally, it is important to be clear that the value blueprint is a diagnostic tool, i.e., it allows one to identify the current status of his/her ecosystem. It does not suggest what (s)he needs to do in order to change this ecosystem towards a more positive outcome, i.e., based on the value blueprint companies still have to choose the strategy $[1,4]$ they will adopt in their ecosystems. This also suggests that the creation of a blueprint is not enough, companies need to continuously monitor their ecosystems and update their blueprints accordingly. This monitoring is done in different forms, including by guaranteeing the true commitment of their partners. We believe that combining information from blueprints with different platform strategies is an interesting aspect to be explored by other researchers. Assuming that these strategies could be somehow modeled and the blueprints represented using a proper notation, one could use modeling techniques to evaluate different platform strategies.

\section{Final Considerations and Future Works}

A project success is no longer solely determined by its execution. Nowadays, it is necessary to have an overview of all the different components involved in a project, i.e., its "context" or broadly speaking its business ecosystem. Success now requires one to manage all components (technology, partnerships, collaborators, investors, retailers, and clients) of this ecosystem. The value blueprint [3] is a tool proposed to help innovators to design products in the context of these broad business ecosystems: instead of focusing solely on the risks associated with the development of a project, this tool also allows one to focus on coinnovation and adoption chain risks that arise from the ecosystem [3]. Those risks would likely go unnoticed otherwise.

We conducted a case study using the value blueprint by modeling the Apple's Watch ecosystem. We chose this product for two reasons. First, because of our interest in wearable technologies, and second because Adner already presents several Apple's ecosystems. We gathered information about the Apple Watch from the Internet focusing on the two risks suggested by Adner: co-innovation and adoption chain risks. By modeling partners, suppliers, investors and other parties as well as the extent to which they are engaged with the Apple Watch, one can assess the risks associated with this product. At the same time, it is also possible to map the minimum valuable ecosystem of a product.

Based on the modeling of this ecosystem, important lessons have been learned about the value blueprint. First of all, while its notation is very simple, it is at the same time limited not allowing (semi-)automatic reasoning of these models. Second, it provides guidelines for the construction of the models, but those guidelines are subjective, so that different stakeholders are likely to create different blueprints. A possible explanation in this case is that such blueprints should be created by teams of stakeholders. Third, this tool provides a diagnostic, i.e., it identifies risks but does not describe how to deal with them. A value blueprint should be combined with ecosystem strategies $[1,4]$ as to mitigate the different identified risks. Finally, it is worth highlighting that the use of the tool is not a warranty of project success.

As for future work, we plan to continue assessing the value blueprint in other scenarios as well as explore computational support for their construction and reasoning.

\section{ACKNOWLEDGMENTS}

Authors would like to thank the funding from $\mathrm{CNPq}$ (process numbers 485070/2013-8 and 310468/2014-0), Chamada 59/2013
MCTI/CT-Info/CNPq (process number 440880/2013-0) and CAPES through a M.Sc. scholarship granted to the first author.

\section{REFERENCES}

[1] Gawer, A., Cusumano, M.: Platform Leadership. Cambridge, MA: Harvard Business Review Press, p. 2. (2002)

[2] Moore, J.F.: Predators and Prey, A New Ecology of Competition. Harvard Business Review, May-June (1993) Available in: http://blogs.law.harvard.edu/jim/files/2010/04/Predators-andPrey.pdf.

[3] Adner, R.: The Wide Lens - What Successful Innovators See That Others Miss Penguin Group (USA) Inc., 375 Hudson Street, New York, New York 10014, USA (2012).

[4] Eisenmann, T., Parker, G., Van Alstyne, M.: Platform Envelopment. Strategic Management Journal, 12(32), p. 1270-1285 (2011).

[5] Ghanam, Y., Maurer, F. and Abrahamsson, P. 2012. Making the leap to a software platform strategy: Issues and challenges. Inf. Softw. Technol. 54, 9 (September 2012), p. 968-984.

[6] TechCrunch. http://techcrunch.com/topic/product/applewatch/

[7] Apple: Informações à imprensa Apple - Apple revela o Apple Watch - o dispositivo da Apple mais pessoal de todos. Available in: https://www.apple.com/br/pr/library/2014/09/09AppleUnveils-Apple-Watch-Apples-Most-Personal-DeviceEver.html. Accessed in October 30 (2014).

[8] Osterwalder, A.: WHAT IS A BUSINESS MODEL? (2008). Available in: http://businessmodelalchemist.com/blog/2008/07/what-isbusiness-model-2.html?rq=canvas

[9] Osterwalder A., Pigneur, Y.: Business Model Generation Innovation in Business Models. (2011)

[10] Osterwalder, A.: The Business Model Ontology a Proposition. Thesis in: L'Ecole des Hautes Etudes Commerciales de l'Université de Lausanne (2004).

[11] Maurya, A.: Why Lean Canvas vs Business Model Canvas? Available in: http://practicetrumpstheory.com/why-leancanvas/

[12] King, R.: Workflow for The Organizational Development Canvas (ODC). The visual layout of the Strategic OrgDev Canvas is inspired by Osterwalder e Pigneur's Business Model Canvas (2010). (2013). Available in: http://www.slideshare.net/RodKing/organizationaldevelopment-canvas-for-lean-startups-and-establishedbusinesses

[13] Sniukas, M.: Take Your Business Model to the Next Level. In Innovation Solutions from Innovation Management. (2013). Available in: http://www.innovationmanagement.se/2013/12/16/take-yourbusiness-model-to-the-next-level/

[14] Yin, R. K. "Case study research: design and methods". Sage Publications, Inc., 1994.

[15] Gil, A.: How to choose research projects (in Portuguese). São Paulo: Atlas, (1991). 
[16] Strauss, A. and Corbin, J., Basics of Qualitative Research: Techniques and Procedures for Developing Grounded Theory, Second. ed. Thousand Oaks: SAGE publications, 1998.

[17] The Seattle Times: Apple broadens its ecosystem with its watch, payment system (2014). Available in: http://seattletimes.com/html/businesstechnology/2024526801 _practicalmac13xml.html. Accessed on Nov 01, 2014.

[18] Patently Apple: Apple Pay: The Digital Wallet that will Rule the World (2014). Available in:

http://www.patentlyapple.com/patently-apple/2014/09/applepay-the-digital-wallet-that-will-rule-the-world.html. Accessed on November 2014.
[19] Appleinsider: iPhone $6 \&$ Apple Watch reveals lived up to the hype for Wall Street, investors have high hopes for Apple Pay (2014). Available in:

http://appleinsider.com/articles/14/09/10/iphone-6-applewatch-reveals-lived-up-to-the-hype-for-wall-street-investorshave-high-hopes-for-apple-pay. Accessed on November 2014.

[20] Apple Webpage. (2015). Available in: https://www.apple.com/watch/overview/. 